\title{
The Malthusian Moment: Global Population Growth and the Birth of American Environmentalism
}

\author{
by Thomas Robertson \\ New Brunswick NJ: Rutgers University Press 2012 \\ ISBN 978-0-81355-272-9 \\ Softcover, $\$ 29.95,291 \mathrm{pp}$.
}

\author{
Reviewed by Simon Dalby \\ Balsillie School of International Affairs \\ Wilfrid Laurier University, Waterloo, Ontario
}

The late 1960s and the lead-up to Earth Day in April 1970 was a tumultuous time in American politics, and not least because of the high-profile focus on environmental themes. One of these-population-was surrounded by contentious political arguments and policy debates, and how to address the issues of what were subsequently to be called "Limits to Growth." Paul Ehrlich's The Population Bomb, the Ballantine paperback book that appeared in mid-1968, crystallized the arguments linking biological models with matters of food supply, pollution, and urban overcrowding. But as Robertson makes very clear, while it was the lightning rod for much of the praise and opprobrium heaped on population policy advocates, there was much more to this controversy than matters which can adequately be labeled as strictly environmental.

Robertson's volume suggests that the larger cultural context of American politics has to be considered if this episode in environmental history is to be explained. For a short time, population had a very high profile as an issue, and he argues that how it came to be also needs to be linked to matters of international politics. In particular, this relates to the declining prominence of the cold war and the relationship between the United States and the developing world, particularly India. Putting the population debate in these larger contexts allows a much more complicated story to be told.

The key to the explication of the argument in this well-written volume is the focus on historical antecedents to the 1960s population discussion. Malthus hasn't often been a popular figure in American deliberations on social matters. The United States is a society premised on abundance of land, resources, and personal opportunity. The frontier beckoned through the nineteenth century, and burgeoning industries and cities always promised more opportunities rather than constraints. That they didn't always deliver-as the urban poor and Southern slaves new all too well-didn't matter in the larger cultural politics of abundance and future promise. Thus, Malthusian arguments are somewhat out of character in American politics. Nonetheless, they appear every now and again, and linked with other issues of population politics - birth control, eugenics, and concerns with conservation and wilderness preservation - they sometimes shape environmental critiques of economic growth.

The domestic context in which environmentalism took hold, and which was driven by concerns with population, relates to the baby boom generation, wherein the American population grew rapidly and simultaneously moved to automobile-dependent suburbs. Growth in numbers was frequently interpreted as the cause of pollution, whereas better explanations referred to the complex political economy of the new modes of consumption and the industrial systems that supplied the rapidly growing appetite for all sorts of consumer goods. But population statistics are simple numerical measures and easy to invoke in a context where youthful enthusiasms are directly related to the experience of being the then-biggest cohort in the American population to date. 
Fears of scarcity, of numbers run amok to threaten many things, were related to the food crisis in India in the mid-1960s. Large shipments of grain from the United States to India were part of the response, one that focused attention on the capabilities of Indian agriculture to deal with what was widely interpreted as the worst consequence of a development-led demographic transition. The Malthusian assumption that agriculture could not expand fast enough to feed the rapidly increasing number of humans provided a simple interpretive scheme for the discussion of global politics. Coupled to earlier assumptions that the big wars of the first half of the twentieth century were caused by population pressures, an argument that Robertson could have more effectively demolished if he had focused on it in a little more detail, the connections between population crisis and international politics was simply drawn.

As Robertson does make very clear, drawing analogies between the Indian situation of wretched impoverishment and the American experience of the consequences of affluence in the 1960s wasn't very sensible, but the comparisons fit a simple narrative demanding population policies to curtail growth of people as the key to dealing with resource constraints and, albeit vaguely articulated, the possibility of warfare and other security problems in future decades. He also emphasizes the key point that fears of migration as a cause of social turmoil linked population to warfare and international politics directly in many of the Malthusian narratives.

Part of the reason these arguments resonated with scientists in particular is that they drew on studies of biological models of predator, prey, and food supply that showed that within limited geographical areas, removing predators sometimes led to population growth and subsequent collapse as food supplies were over-grazed. Clearly there are food supply limitations in nature, and humanity is not immune to similar constraints; therefore, it follows that overpopulation is a problem for humanity, too. But the specific contexts of how people are fed, the political economy of food supply, and the possibilities of industrial farming and green revolution innovations are frequently discounted in these discussions. As Robertson makes very clear, the politics of food supply and uneven access to wealth explain so much more than simple biological models do.

The great strength of this volume is the way the author teases out how ecological models and biological thinking shaped the population discussion in the 1960s, and how Ehrlich in particular rethought his formulations in light of the nuances of political matters, and re-emphasized his critiques to be more sensitive to his audience. He needed to do so in part because his biological arguments about nature clashed so obviously with Catholic Church teachings about sex and procreation as being "natural." Starting with individual behaviours or with biological models of whole populations makes for very different claims over what is the given natural context within which judgment, and hence policy, should be made.

The population "crisis" abated in the United States nearly as fast as it arose. In the 1970s, the ascendancy of the New Right and the cultural politics of technological optimism, epitomized in the Reagan presidential campaign of 1980, contrasted with the Malthusian pessimism of President Carter and some themes in the previous Ford and Nixon administrations. Through these years, a widespread consensus on population growth reduction and the need for pollution control had existed, and policy innovations dealt with at least some of the Malthusian concerns. Elsewhere around the globe, the green revolution and rising affluence in many places lessened the sense of a global food crisis; India no longer needed large shipments of food aid. Policies on population, birth control, and female health and literacy campaigns, coupled with rapid urbanization, began to slow the demographic expansion, and attention shifted away from population to a re-invigorated consumption economy, as well as resurgent worries about nuclear warfare in the Reagan years.

There is a cyclical pattern to concerns about population and environment, but clearly the simplistic biological models that underpinned the Malthusian fears of the 1960s have been shown to be much less than adequate modes of analysis or policy prescription. But some of these themes have recurred again much more recently. The climate change discussion-and in particular, arguments that the civil war in Syria is related to climate change-induced drought-caused scarcity-bears some clear resemblances to the Malthusian narratives of the 1960s. Such arguments are now often met by those that emphasize the failure of the Syrian state to deal with migrants in its cities as being key to the initial political unrest. The complex politics of conflict, rather than simple arguments about numbers alone, provide more plausible explanations of recent events. Robertson's concluding sentence seems very apt indeed: "Ultimately, if we are to solve the problems presented by global issues such as 
population growth, including climate change, we will have to understand the ways in which human beings are subject to nature's laws, but are not just another species." 